\title{
MODELAMENTO MATEMÁTICO DAS CURVAS DE DESCARBURAÇÃO E DESIDROGENAÇÃO NO RH THYSSENKRUPP CSA *
}

\author{
Beatriz de Paula Lopes ${ }^{1}$ \\ Daniel A. G. de Carvalho', \\ Heber V.G. Segundo ${ }^{3}$, \\ Leonardo Demuner, \\ Marcos A. V Júnior ${ }^{5}$, \\ Raissa Santos Salgado, \\ Roberto P. Tavares ${ }^{7}$
}

\begin{abstract}
Resumo
Atualmente, a exigência do mercado pela produção de aços de alta qualidade aliada a redução de custos, impulsiona maiores investimentos em novas tecnologias e a busca pelo melhor conhecimento dos processos que ocorrem na usina siderúrgica. $O$ desgaseificador $\mathrm{RH}$ tem-se revelado um equipamento fundamental para produção de aços ultra low carbon, tipo cada vez mais solicitado pelos maiores consumidores de aço. Diante disso, este trabalho visa a elaboração de um modelamento matemático das curvas de descarburação e desidrogenação no $\mathrm{RH}$ thyssenkruppCSA. A geração dessas curvas possibilitou o estudo do comportamento do teor de carbono e hidrogênio durante o tratamento das corridas no reator. Os resultados demonstram que o teor de carbono médio obtido não está dentro do esperado, conforme previsto pelo comissionamento. No entanto, a desidrogenação pode ser considerada como satisfatória.
\end{abstract}

Palavras-chave: Refino secundário, Desgaseificador a vácuo, Descarburação, Desidrogenação.

\begin{abstract}
Currently, a market requirement for the production of high quality steels associated to a reduction of costs promotes larger investments in new technologies and a search for increased knowledge of the processes that occur in steel plant. The $\mathrm{RH}$ degasser has proved to be a fundamental equipment for the production of ultra low carbon steels, a type increasingly requested by the largest consumers of steel. Therefore, this work aims at the elaboration of a mathematical modeling of decarburization and dehydrogenation curves in $\mathrm{RH}$ thyssenkruppCSA. The establishing allowed a study of the behavior of the carbon and hydrogen content during the treatment of heat in the reactor. The results demonstrate that the carbon content obtained is not within the expected range, however, a dehydrogenation can be considered satisfactory.

Keywords: Secondary Refining, Vacuum Degasser, Decarburization, Dehydrogenation.

Engenheira Metalurgista da thyssenkruppCSA, Rio de Janeiro, RJ, Brasil

Engenheiro Metalurgista e Mestre da thyssenkruppCSA, Rio de Janeiro, RJ, Brasil

Engenheiro Metalurgista da thyssenkruppCSA, Rio de Janeiro, RJ, Brasil

Engenheiro de Produção e Gerente da aciaria thyssenkruppCSA, Rio de Janeiro, RJ, Brasil

Engenheiro Químico da thyssenkruppCSA, Rio de Janeiro, RJ, Brasil

Aluna de Graduação do Curso de Engenharia Metalúrgica da UFMG, Belo Horizonte, MG, Brasil

Sócio da ABM; Engenheiro Metalurgista; Professor Doutor do Departamento de Engenharia

Metalúrgica da UFMG, Belo Horizonte, MG, Brasil
\end{abstract}




\section{INTRODUÇÃO}

A thyssenkruppCSA é um complexo siderúrgico, com capacidade de produção de 5 milhões de toneladas de placas de aço por ano. A usina apresenta um processo semi integrado, contando com diversas unidades de produção: sinterização, coqueria, alto forno, aciaria e lingotamento contínuo, que foram projetadas para serem próximas umas das outras, favorecendo a otimização de serviço e agilidade [1].

A aciaria, referência mundial em produtividade, consiste de duas estações de dessulfuração, dois convertedores LD - 330 ton e uma etapa de tratamento da panela (LTS - Ladle Tratament Station). Além disso, a aciaria também é composta pelo refino secundário, que fica sob responsabilidade dos desgaseificadores: RH (Ruhrstahl- Heraeus), em conjunto com o AHF.

A exigência pela qualidade e redução de custos do processo promove um aumento das buscas por novas tecnologias e uma melhoria do conhecimento dos processos realizados na usina. A demanda de aços com requisitos de qualidade mais rigorosos tem exigido teores de carbono cada vez menores, conhecidos como aços ultrabaixo carbono e aços livres de intersticiais. Estes tipos de aços são de grande aplicação, principalmente, na indústria automotiva, setor em que são requeridos aços com faixas extremamente estreitas, variando de $0,0015 \%$ a $0,0025 \%$ como o "Bake Hardening" [2].

O desgaseificador a vácuo RH é o principal equipamento utilizado para produção desses aços com ultrabaixos teores de carbono e é considerado um equipamento chave na siderurgia moderna, segundo Tembergen (2007) [3]. Além da descarburação as principais funções do reator RH são: remoção de hidrogênio e nitrogênio, tratamendo de limpidez da corrida (reduzir inclusões), ajuste de composição química e aquecimento.

O tratamento para descarburação caracteriza-se pela reação do carbono dissolvido no aço com o oxigênio, produzindo gás $\mathrm{CO}$, que é retirado pelo sistema de vácuo. A reação de descarburação se baseia numa reação dependente da pressão e pode ser expressa pela Equação (1):

$$
\mathrm{C}+\mathrm{O}=\mathrm{CO}_{(\mathrm{g})}
$$

A desidrogenação também se dá pela diminuição da pressão parcial desse na câmara de vácuo e da injeção de gás inerte [2].Podendo ser expressa pela Equação (2):

$$
2 \mathrm{H}=\mathrm{H}_{2}(\mathrm{~g})
$$

O princípio do desgaseificador RH consiste na circulação do aço líquido entre a panela e uma câmara, onde ocorre a produção do vácuo. Neste processo, a intensidade da circulação do aço afeta não só a velocidade das reações, como também a taxa de homogeneização do material na panela.

Durante o tratamento das corridas, as duas pernas (snorkels), que constituem uma parte do vaso, são imersas no aço contido na panela, estabelecendo uma conexão entre a panela e a câmara, o que permite a circulação do aço. O processo de imersão das pernas, pode ser dado pela elevação da panela ou pelo abaixamento do vaso. Para promover a circulação do aço, além do vácuo produzido no sistema, ocorre a injeção de gás inerte, geralmente argônio, por uma das pernas [4] como mostrado na Figura 1: 


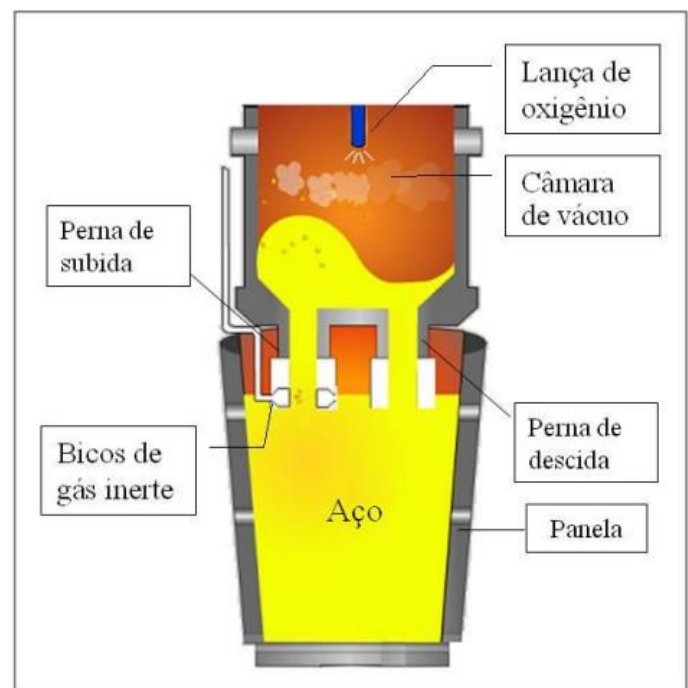

Figura 1: Vista esquemática do desgaseificador $\mathrm{RH}$ mostrando a circulação do aço através das pernas (Silva et al, 2004)

O processo RH depende de diversas variáveis, como a área transversal interna do vaso, vazão de argônio injetada nas pernas de subida, a taxa de circulação do aço panela/vaso e do vácuo [2]. Este último exercendo grande influência, principalmente, na eficiência da descarburação, etapa fundamental para que se atinja os valores mínimos dos teores de carbono necessários nos aços ultra baixo carbono.

No presente trabalho foi desenvolvido um estudo para avaliar o atual comportamento da descarburação e desidrogenação em corridas tratadas no reator RH. De forma a obter modelos matemáticos teórico, capaz de prever a evolução das concentrações de carbono e hidrogênio dissolvidos no aço. A partir dos modelos desenvolvidos, avaliar os mecanismos envolvidos nos tempos de tratamento (DeC e DeH), e subsequente a essa avaliação, realizar análise de sensibilidade, variando a pressão de vácuo para a variável tempo e pressão de vácuo.

\section{MATERIAIS E METÓDOS}

\subsection{Descrição RH}

O presente projeto tem como finalidade realizar um estudo exploratório, relacionado à curva de descarburação e desidrogenação no $\mathrm{RH}$ T-COB de $330 \mathrm{t}$, da aciaria thyssenkruppCSA.

O equipamento $\mathrm{RH}$, em estudo, consiste em um vaso bipartido, com diâmetro interno de $2650 \mathrm{~mm}$. Atráves de um sistema hidráulico, ocorre a elevação da panela, até que os dois snorkels do vaso estejam imersas no aço. O snorkel de subida contém 16 ventaneiras, com diâmetro de $3 \mathrm{~mm}$. Associado ao vaso $\mathrm{RH}$, tem-se a bomba de vácuo, formada por 7 ejetores e 3 condensadores [5]. A figura 2 ilustra o equipamento descrito: 


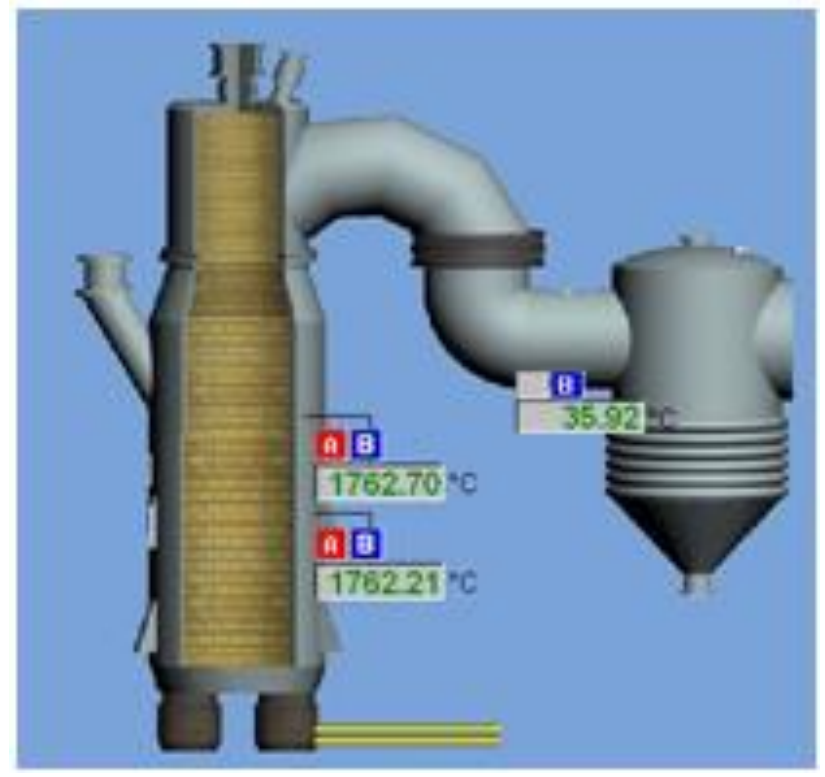

Figura 2: Vista frontal do equipamento RH T-COB thyssenkruppCSA

Para a execução dos experimentos e buscando avaliar os teores de carbono, foram utilizados métodos de amostragem, seguidas por análises realizadas, em laboratório, localizado na própria aciaria. A partir dos resultados destas amostras foi traçada a curva de descarburação.

\subsection{Amostragem e análise}

O projeto foi divido em três etapas: A primeira consistiu de visitas na área, em busca de um melhor entendimento do processo $\mathrm{RH}$, através de levantamento de informações técnicas e teóricas. Na segunda etapa, foram retiradas 15 amostras por corrida, ao longo de 20 corridas do tipo IF (Intersticial free). Para retirada das amostras utilizouse um amostrador IF do tipo pirulito Iollipop, que apresenta revestimentos especiais para prevenção de contaminação da amostra por outros elementos (principalmente quanto ao teor de carbono). $O$ amostrador utilizado é composto por uma coquilha para coleta e solidificação do aço, um filete de zircônio para desoxidação da amostra, um tubo de quartzo, uma tampa de aço baixo carbono e um invólucro cerâmico [4], conforme Figura 3. 


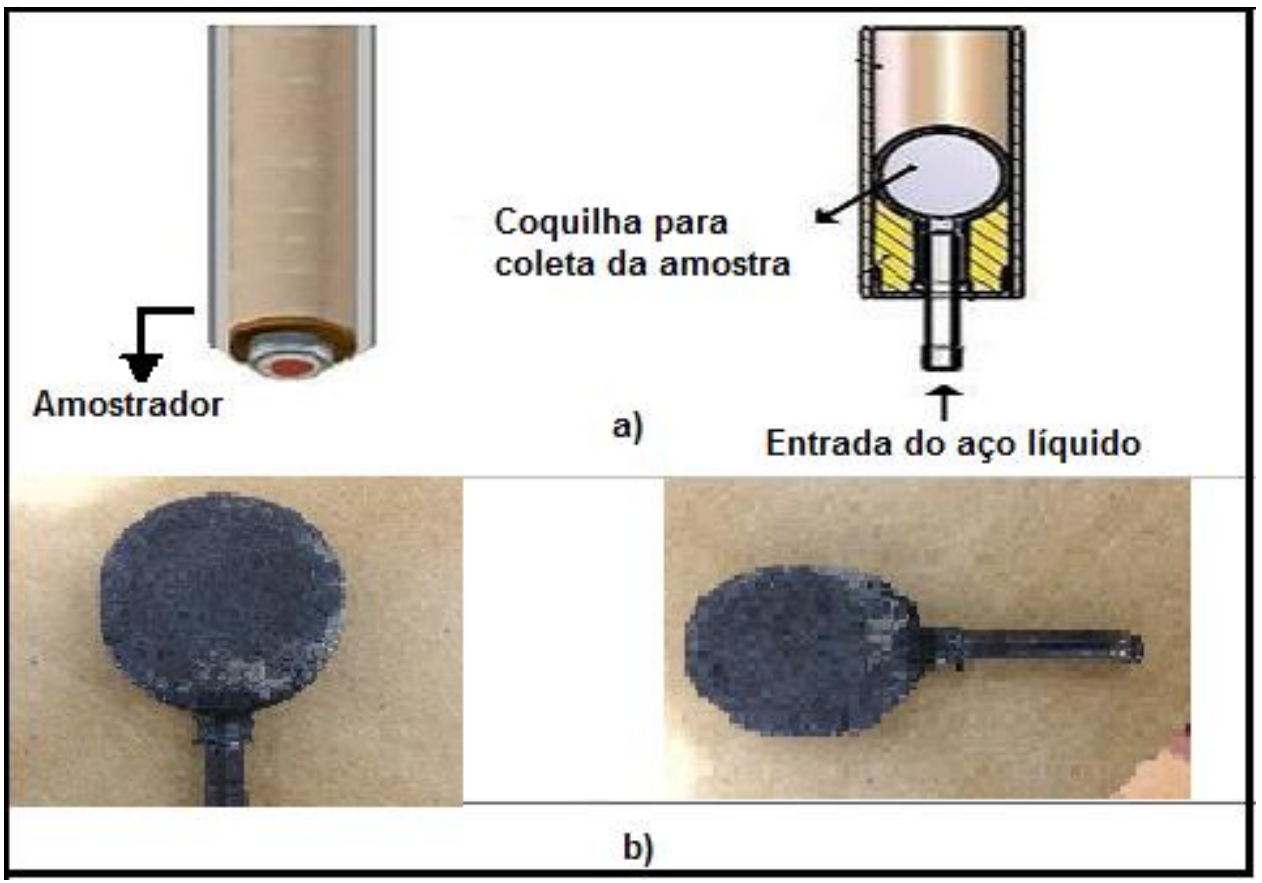

Figura 3: Esquema do amostrador utilizado (a) e as amostras de aço (b).

As amostras de aço ilustradas foram analisadas em equipamentos presentes no laboratório da própria aciaria, sendo eles: Espectrômetro de Emissão Òtica(OES), que consiste em uma análise baseada na queima da superfície da amostra por uma sequência rápida e intensa de centelhamento em um ambiente de argônio. E o ELTRA CS800, técnica analítica por meio de um forno de indução, onde a amostra é fundida com o auxílio de aceleradores e o produto resultante da queima é detectado através de células infravermelhas, liberando, de acordo com a detecção, resultado de $\mathrm{C}$ e $\mathrm{S}$. A terceira etapa compreendeu as análises dos resultados, registrando-os em tabelas que, em seguida, foram convertidos em gráficos. Assim, nesse trabalho foram analisadas cerca de 300 amostras de aço no total para caracterização da curva de descarburação.

\subsection{Modelamento matemático das curvas $\mathrm{DeC}$ e DeH}

Para determinação desta curva foi proposto um modelo baseado na Equação (3) abaixo, proposta por Stolte [6] e [7]:

$$
C_{t}=C_{i} \exp \left(-k_{c} t\right)
$$

Sendo: $C_{t}=$ concentração instantânea de carbono $(\mathrm{ppm})$;

$\mathrm{C}_{\mathrm{i}}=$ concentração inicial de carbono $(\mathrm{ppm})$;

$\mathrm{k}_{\mathrm{C}}=$ constante de velocidade de descarburação $(\min -1)$;

$\mathrm{t}=$ tempo (minutos);

Além dos teores de carbono, este trabalho objetivou investigar os teores de hidrogênio. Dessa maneira, os experimentos foram realizados em corridas do tipo aço comum, tratadas no $\mathrm{RH}$. A retirada de amostras foi executada através de um sistema de sensor $\mathrm{Hydris}^{\circledR}$, que utiliza o princípio da distribuição de pressão parcial de hidrogênio entre a fase de gás e a fase líquida. A imersão da sonda pelo operador era feita em intervalos de, aproximadamente, 5 minutos. Através desse método, 
realizaram-se amostragem em 15 corridas aço comum, totalizando cerca de 75 amostras.

Com base nesses resultados fornecidos pelo sensor Hydris ${ }^{\circledR}$, gerou-se uma curva de desidrogenação. Para fins práticos, a caracterização da curva foi fundamentada na expressão cinética simplificada da desidrogenação, determinando empiricamente o valor de $\mathrm{k}_{\mathrm{H}}$ do equipamento [7] e [8]. A Equação (4) toma a forma:

$$
\ln \left[\frac{H t-H c}{H 0-H c}\right]=-\mathrm{k}_{\mathrm{c}} \cdot \Delta t
$$

Segundo Susaki, o valor da constante de velocidade aparente da desidrogenação varia de acordo com as condições operacionais, sendo aproximadamente 0,08 $\mathrm{min}^{-1}$.

É importante ressaltar que os experimentos durante as corridas, foram realizados em escala industrial e com inúmeras variáveis que possivelmente podem ter interferido na obtenção de uma maior precisão.

\section{RESULTADOS E DISCUSSÃO}

Para caracterização da curva de descarburação foi utilizado um método simples e razoavelmente preciso, proposto por Stolte, Gerd et al. (2007), já citado anteriormente. A Figura 4 apresenta o perfil da curva obtida:

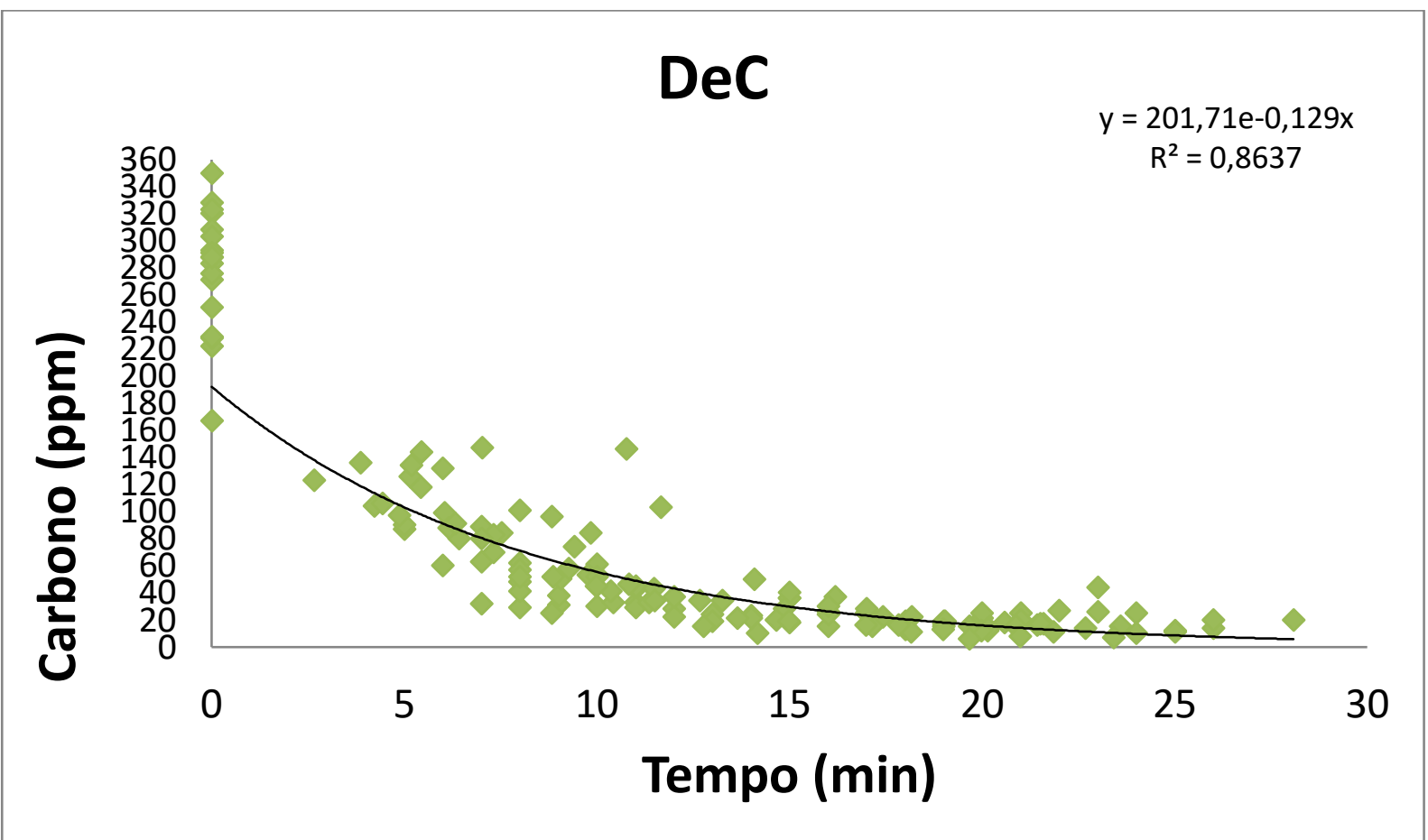

Figura 4: Variação do teor de carbono(ppm) ao longo do tempo de tratamento(min)

Analisando a curva acima, pode se inferir que os valores de carbono sofrem uma queda acentuada até, aproximadamente, 17 minutos de tratamento. Após este tempo, os valores parecem não sofrer grandes alterações, mantendo-se mais estáveis ao final do tratamento.

Ao realizar uma subsequente análise, é possível perceber que as corridas apresentaram comportamentos diferentes ao longo do tempo, evidenciado pelo decaimento do carbono, que não ocorreu de forma similar na maioria delas. Dessa 
maneira, foi realizado um novo tratamento dos dados, buscando um maior refino dos resultados e um melhor parecer do processo.

Com base em uma fundamentação empírica, o novo tratamento consistiu numa análise "corrida a corrida", calculando o kc para cada um, agrupando as corridas em que a pressão de vácuo apresentou comportamento similar e retirando aquelas com pumpdown bastante distinto das demais. Então, para cada grupo que apresentava pressão média semelhante, foi realizado o cálculo para obtenção do kc médio. Em seguida, foi feito um "malabarismo algébrico", baseado em uma fundamentação teórica e assim encontrou-se uma relação linear entre os logaritmos neperianos da pressão média (In $\mathrm{P}_{\text {média) }}$ e os logaritmos neperianos do kc [9].

A partir dessa relação linear encontrada, que demonstrou índice de confiabilidade satisfatório $\left(R^{2}=0,755\right)$, pôde-se realizar uma análise de sensibilidade, variando tempo de tratamento e pressão de vácuo. O teste de sensibilidade é ilustrado pelas Tabela 1 e Figura 5 abaixo:

Tabela 1: Teste de sensibilidade (carbono)

\begin{tabular}{|c|c|c|c|c|c|}
\hline & & \multicolumn{4}{|c|}{ Pressão (mbar) } \\
\hline & & $2 \mathrm{mbar}$ & $6 \mathrm{mbar}$ & $10 \mathrm{mbar}$ & 14mbar \\
\hline \multirow{6}{*}{ 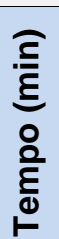 } & 5 & 250 & 250 & 250 & 250 \\
\hline & 10 & 121 & 137 & 145 & 157 \\
\hline & 15 & 58 & 76 & 84 & 98 \\
\hline & 20 & 28 & 42 & 49 & 62 \\
\hline & 25 & 14 & 23 & 28 & 39 \\
\hline & 30 & 7 & 13 & 16 & 24 \\
\hline
\end{tabular}

\section{Carbono x tempo}

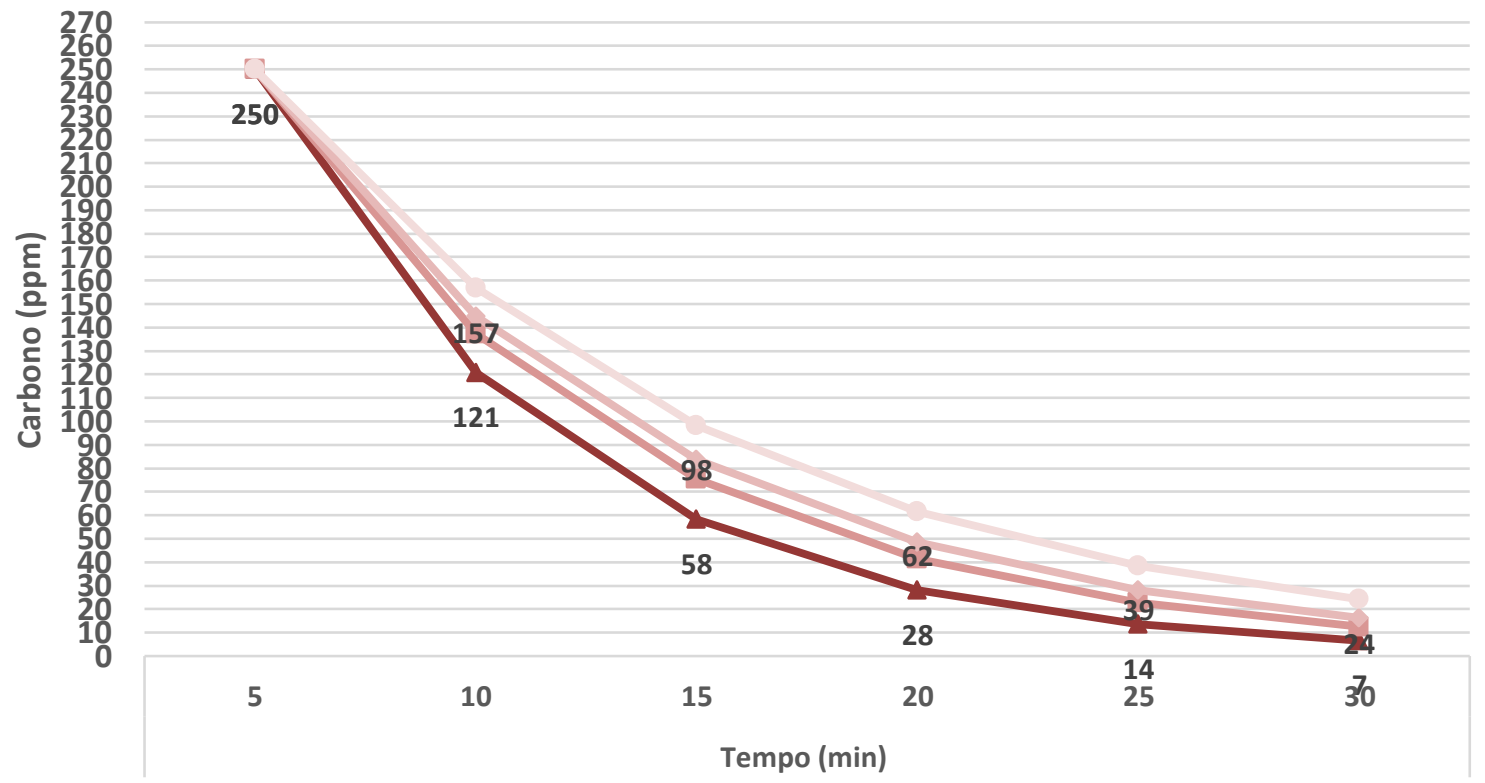

$\longrightarrow$ Pressão $2 \mathrm{mbar}=$ Pressão $6 \mathrm{mbar}$

Pressão 10mbar

Pressão 14mbar

Figura 5: Análise de sensibilidade para prever o teor de carbono em função da pressão de vácuo e tempo de tratamento

Através do gráfico acima, é possível destacar que nas corridas em que se atinge menores pressões de vácuo, o teor de carbono sofrerá maior redução em menor tempo. Essa afirmação pode ser evidenciada pela significativa diferença no teor de 
carbono final entre corridas com pressão de vácuo igual a $2 \mathrm{mbar}$ e $6 \mathrm{mbar}$, para tempo de 25 minutos. Dessa forma, torna-se interessante para o processo industrial atingir uma menor pressão em menor tempo, pois possibilita uma redução no consumo de vapor, principal parâmetro nos custos de corridas tratadas no $\mathrm{RH}$, diminuição do desgaste do refratário e, consequentemente, uma maior produtividade.

Além da curva da descarburação foi realizada a determinação da curva de desidrogenação, baseada na equação proposta Sumida(1983)[9], já referida anteriormente. A Figura 6 apresenta a curva obtida:

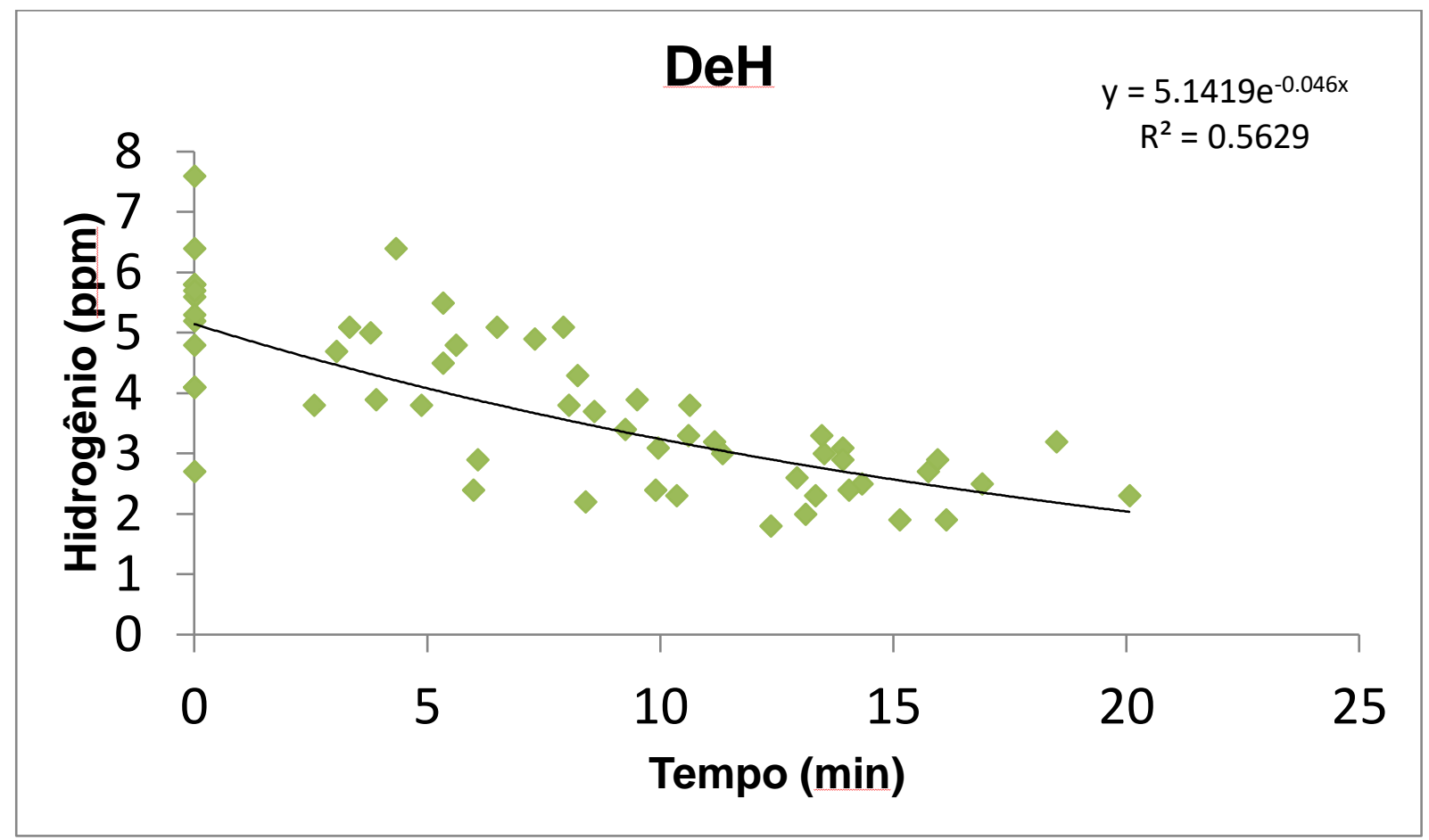

Figura 6: Variação do teor de hidrogênio (ppm) ao longo do tempo de tratamento (min)

A Figura 6 apresenta uma curva que representa o comportamento do teor de hidrogênio, ao longo de corridas que sofreram tratamento no $\mathrm{RH}$. O decaimento do hidrogênio durante os primeiros minutos ocorre de forma lenta e o teor médio alcançado no final da corrida foi igual a 3,0 em um tempo de 15 minutos.

Conforme, realizado na descarburação, optou-se por um melhor refino dos resultados obtidos na desidrogenação, por meio do tratamento de dados, "corrida a corrida".

Dessa maneira, foi possível gerar um gráfico hidrogênio em função do tempo, variando o parâmetro pressão de vácuo. O gráfico citado é apresentado na Figura 7: 


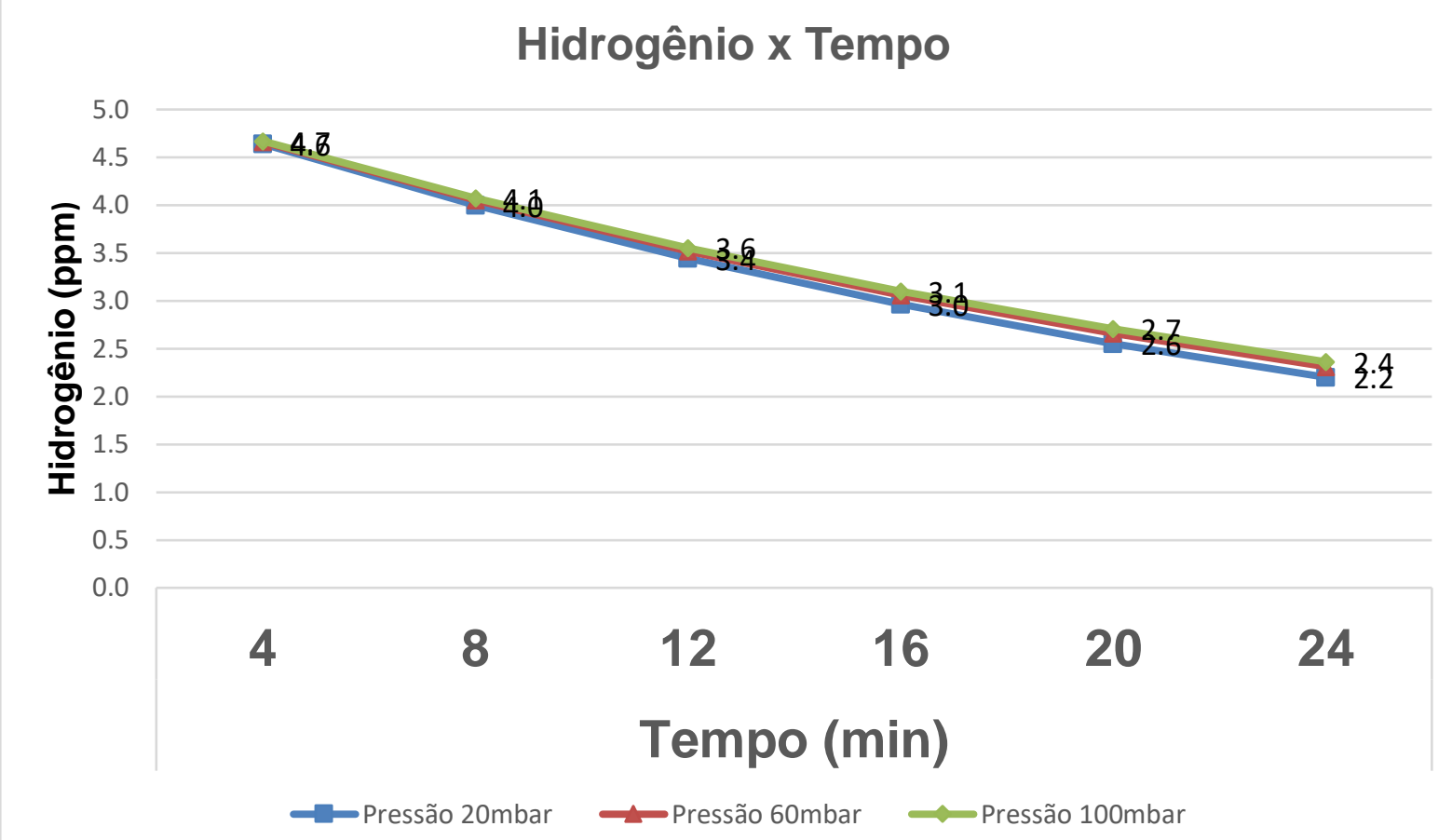

Figura 7: Análise de sensibilidade para prever o teor de hidrogênio em função da pressão de vácuo e tempo de tratamento

Sabendo que a remoção de hidrogênio não necessita de pressões de vácuo muito baixas, por isso a escolha de pressões maiores para realizar a análise de sensibilidade. Por meio desse teste, observa-se que teor de hidrogênio atinge valores próximos a 2,2 ppm, em 24 minutos se utilizado pressão igual a 20mbar e teor de 2,4 ppm a 100 mbar.

Vale ressaltar que para validação dos modelos foram realizadas análises estáticas e para criação dos testes de sensibilidade foram consideradas condições de um banho estático, em ambos os casos (Descarburação e desidrogenação).

\section{CONCLUSÃO}

Com base nos resultados gerados ao longo do projeto in Company foi possível estabelecer as seguintes conclusões:

1. Os modelos podem subsidiar o comportamento dos teores de carbono e hidrogênio nas corridas $\mathrm{RH}$;

2. A importância em atingir vácuo profundo em menor tempo e conseguir mantêlo por maior tempo durante o processo de tratamento;

3. A necessidade de manutenções periódicas do equipamento $\mathrm{RH}$, principalmente, ao que se refere a bomba de vácuo, componente sensível e que exige uma maior atenção, a fim de possibilitar um funcionamento satisfatório para o alcance do menor vácuo; 


\section{AGRADECIMENTOS}

Os autores agradecem à thyssenkruppCSA, pela oportunidade da realização do projeto em suas dependências, disponibilizando equipamento, material e pessoal necessário para realização dos testes. Aos engenheiros Daniel A. G de Carvalho e Marcos Viana pelo apoio, suporte técnico. Ao gerente Leonardo Demuner, coordenador Heber Segundo, à Eng. de Processos do RH, Beatriz Lopes, ao Luciano do laboratório, pela acolhida e interesse demonstrado ao trabalho. $\mathrm{E}$ aos operadores da equipe $\mathrm{RH}$ que possibilitaram a execução desse projeto.

\section{REFERÊNCIAS}

1. thyssenkruppCSA [página da internet]. Acesso em 10/07/2017. Disponível em https://www.thyssenkrupp-csa.com.br/pt-br/

2. SILVA; M. Variação da taxa de descarburação para vários padrões de injeção de argônio na perna de subida do desgaseificador a vácuo $\mathrm{RH}$. [Dissertação de Mestrado em metalurgia extrativa]. Escola de Engenharia: Universidade Federal de Minas Gerais, Belo Horizonte; 2010.

3. Tembergem D, Teworte R, Robey R. Ladle treatment using RH metallurgy. In: MTP International, mar. 2007.

4. Moura E, Rocha J, Mota M. Modelamento da curva de descarburação nos aços UBC no RH da thyssenkruppCSA Siderúrgica do Atlântico. [Trabalho apresentado na conclusão do curso de Pós-Graduação em Metalurgia] Faculdade Pitágoras; 2011.

5. CSA Technical Documentation Steelmaking, August 2007;

6. Stolte, G. Secondary metallurgy: Fundamentals, Processes, Applications.

Publisher: Düsseldorf: Stahleisen, cop. 2007.

7. Stolte, G. Secondary Metallurgy: Fundamentals, Processes, Applications (1st Edition). Hardcover, 216 Páginas, Publicado em 2002.

8. Sumida N,Fujii T, Oguchi M., Morishita H., Yoshimura K., Sudo F.: "Production of Ultra Low Carbon Steel by Combined Process f Bottom Blown Converter an RH Degasser", Kawasaki Steel Techinical Report, No.8, pp - 69-76, setembro, 1983;

9. Sumida N,Fujii T, Oguchi M., Morishita H., Yoshimura K., Sudo F: "Production of Ultra Low Carbon Steel by Combined Process $f$ Bottom Blown Converter an RH Degasser", Kawasaki Steel Giho, 152(1983)2; 